"Dark personality traits and job performance of employees: The mediating role of perfectionism, stress, and social media addiction"

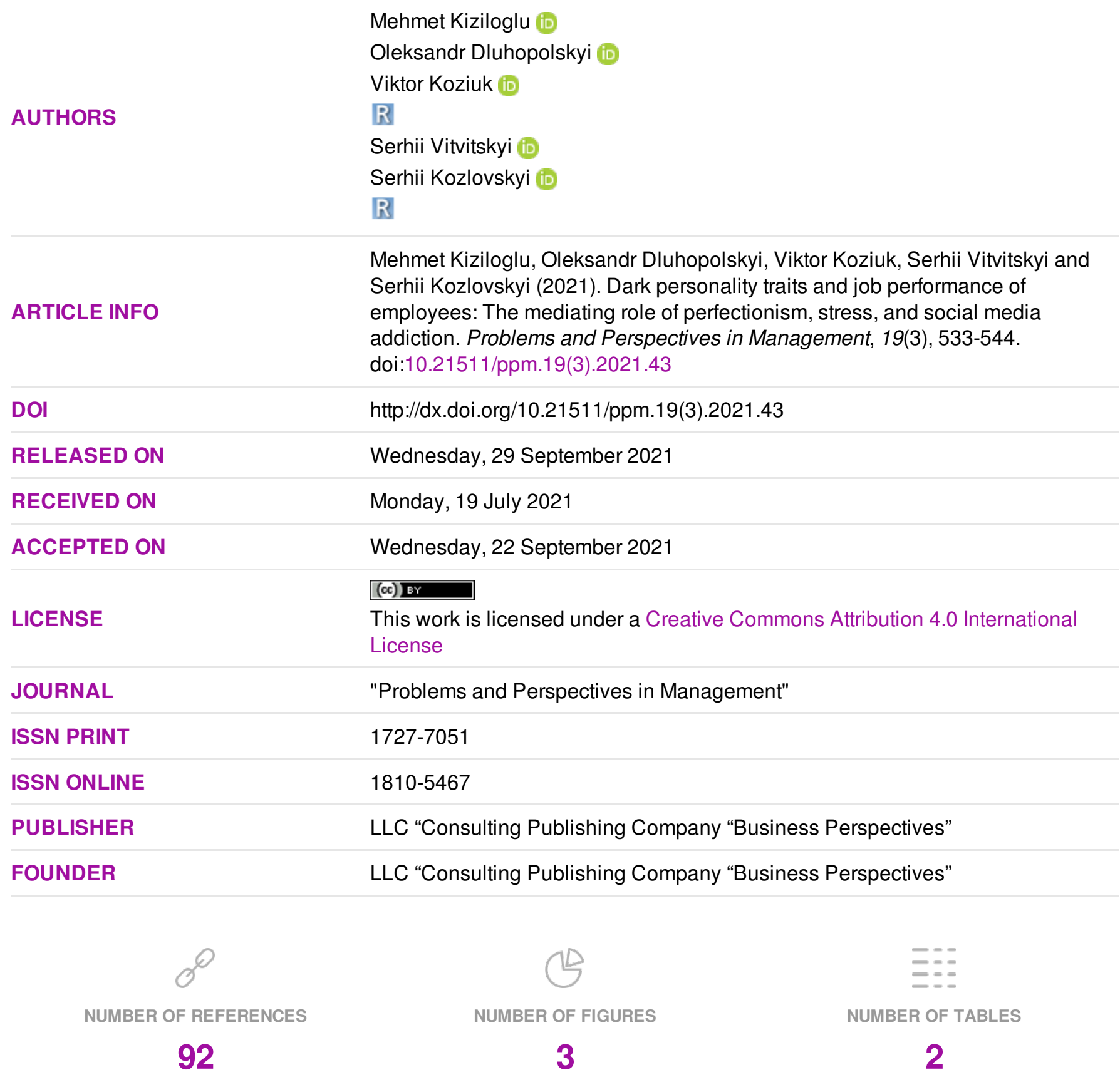

(c) The author(s) 2021. This publication is an open access article. 


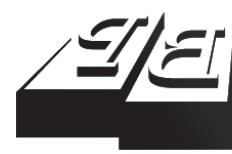

BUSINESS PERSPECTIVES

()

LLC "CPC "Business Perspectives" Hryhorii Skovoroda lane, 10, Sumy, 40022, Ukraine www.businessperspectives.org
Received on: $19^{\text {th }}$ of July, 2021 Accepted on: 22 $2^{\text {nd }}$ of September, 2021 Published on: $29^{\text {th }}$ of September, 2021

(C) Mehmet Kiziloglu, Oleksandr Dluhopolskyi, Viktor Koziuk, Serhii

Vitvitskyi, Serhii Kozlovskyi, 2021

Mehmet Kiziloglu, Dr., Associate Professor, Management and Organization Department, Pamukkale University, Turkey.

Oleksandr Dluhopolskyi, Dr. Ec. Sc., Professor, West Ukrainian National University, Ternopil Volodymy Hnatiuk National Pedagogical University, Ukraine.

Viktor Koziuk, Dr. Ec. Sc., Professor, Head of Economics Department, West Ukrainian National University, Ukraine.

Serhii Vitvitskyi, Dr. Law Sc., Professor, Rector of Donetsk State University of Internal Affairs, Ukraine.

Serhii Kozlovskyi, Dr. Ec. Sc., Professor, Department of Entrepreneurship, Corporate and Spatial Economics, Vasyl' Stus Donetsk National University, Ukraine. (Corresponding author)

Mehmet Kiziloglu (Turkey), Oleksandr Dluhopolskyi (Ukraine), Viktor Koziuk (Ukraine), Serhii Vitvitskyi (Ukraine), Serhii Kozlovskyi (Ukraine)

\title{
DARK PERSONALITY TRAITS AND JOB PERFORMANCE OF EMPLOYEES: THE MEDIATING ROLE OF PERFECTIONISM, STRESS, AND SOCIAL MEDIA ADDICTION
}

\begin{abstract}
The purpose of this study was to explore the indirect and direct relationships of Big5 and dark personality traits (i.e., extroversion, neuroticism, agreeableness, openness, conscientiousness, narcissism, Machiavellianism, psychopathy, sadism, and spitefulness) with job performance via perfectionism, stress, and social media addiction. A total of 514 private sector employees filled out a query sheet that included the assessment tools for the variables. Path analysis using a multiple mediation model indicated that neuroticism was negatively directly and indirectly related to job performance via stress and social media addiction. Machiavellianism and spitefulness were directly positively associated with job performance, and Machiavellianism-related higher social media addiction diminished the direct positive effect of Machiavellianism on job performance, indicating complex relationships. Furthermore, stress, social media addiction, and perfectionism were related to different personality traits positively and negatively. Findings of the present study suggest that an anti-social personality may promote higher job performance. However, job performance may be adversely affected by the adverse consequences relating to these traits. Professionals and firms that at tempt to increase job performance should take anti-social personality traits and their complex effects on job performance into account.
\end{abstract}

\section{Keywords}

JEL Classification

\section{INTRODUCTION}

The last century is characterized by a large number of studies of psychology on the relationship between work performance and personality. Personality was seen as an important factor for productivity analysis. It is a behavior that distinguishes one person from another (Beer \& Brooks, 2011; Tuteja \& Sharma, 2017; Cherry, 2019). Personality makes it possible to understand whether a person will be able to perform a certain job or not. Performance is the result of skills, knowledge, effort, and role abilities. It is customary to different individuals based on their personal traits. These features make them suitable for a certain type of work. It is therefore critical to know how different factors contribute to work (Yohannes, 2020), especially through stress and social media.

Digitalization affects substantial transformation of job nature as well as labor markets. Traditional HR visions on how each trait of potential employee related to performance on job-place may not be relevant in the new era. At the same time, a large fraction of traditional econom- 
ic and social interactions may still require more common traits that rely on rational (for each culture) expectations about performance on the job placement. While labor economics and HR practices are enriched by behavioral studies, that tie economics and psychology, further understanding of relations between traits and performance are needed. This paper uses the empirical approach grounded on data from a questionnaire that helps to avoid some theoretical biases in modeling the relations between traits and employee performance.

The paper is structured into six sections. Following the introduction, Section 1 presents a brief literature review of Big- 5 and dark personality traits. Section 2 is devoted to applying a methodological approach and research methods. In Section 3, results from correlation analysis are presented. In Sections 4 and 5, data models are interpreted and commented on.

\section{LITERATURE REVIEW}

The first person to investigate the hypothesis that a complex taxonomy of human personality traits could be obtained by selecting a language was F. Galton (Galton, 1884; Shrout \& Fiske, 1995). Later, Allport and Odbert (1936) applied Galton's hypothesis in practice, extracting more than 4,000 adjectives, which described the observed and relatively constant features in dictionaries at the time. In 1949, a pioneering multivariate study of personality was committed by J. Guilford (Guilford, 1949; Musek, 2017), who analyzed ten personality factors. Later, Mischel (1968) stressed that attitudes and behavior change depend on the situation and are not stable.

The paradigm returns to the adoption of the Big-5 model that emerged in the early 1980s (Goldberg, 1980; Joubert \& Venter, 2013). Until 1983, experiments showed that the forecast of personal models is best correlated with actual behavior in stressful emotional postures, in contrast to the typical interview in neutral emotional postures (Boyle, 1983; Boyle et al., 1995).

New methodological approaches increasingly confirmed theories of personality during the 1980s (Kenrick \& Funder, 1988; Epstein \& O'Brien, 1985). Today, psychologists agree that both personal and situational factors are important for recording changes in human behavior (Lucas \& Donnellan, 2009; Schwartz et al., 2013; Soto, 2018). In the early 1980s, Goldberg (1981) began a lexical project based on five wide factors that were labeled the Big-5 (five-factor model - FFM). DeYoung et al. (2016) investigated the Big-5 model and how the five common factors are compatible with the 25 personality inventory scales (PID-5) for the DSM-5. The number of valid facets might be limited only by the number of traits that can be shown to have discriminant validity.

Gender studies of the Big-5 inventory showed that women are mostly slightly superior to men in neuroticism, extraversion, pleasure, and integrity (Costa et al., 2001). However, the gender difference in personality traits is greater in the more developed, wealthy, and gender-egalitarian countries. Men in highly developed regions of the world are less neurotic, extroverted, honest, and pleasant compared to men living in less affluent regions of the world. Women, as a rule, do not differ in personality traits in different regions of the world (Schmitt et al., 2008). Yet most literature sources do not consider the moderating effects of gender on the impact of personality traits on performance (Cubel et al., 2016).

Cultural differences also affect the Big-5. The degree of assessment of individualism in the country correlates (Kozlovskyi et al., 2021) with the ordinary extraversion, while individuals belonging to cultures that perceive significant imbalances in their power structures tend to be slightly higher than honesty (McCrae et al., 2005; Koziuk et al., 2018).

Some companies and organizations around the world evaluate people based on the personality traits of the Big-5. Studies have confirmed that individuals who are considered leaders tend to show fewer neurotic traits, sustain a higher level of openness, a balanced level of integrity, and a 
balanced level of extraversion (Judge et al., 2002). Further systematic studies link burnout at work and home with neuroticism, and extraversion with permanent positive work experience (Mehta, 2012). Some studies show that the results of professional activities are correlated with the personality traits of Big-5. Integrity is the highest level of overall performance (Sackett \& Walmsley, 2014). Important predictors of promotion goals are extraversion, integrity, and pleasure (Spurk \& Abele, 2011). FFM-based inventories have a long shelf life.

It is well known that the role of the individual in the performance of work is crucial because certain individual traits contribute to career growth at work. The results of various studies, in particular Salgado (1997) and Vinchur et al. (1998), have shown that the Big-5 dimensions of personality are work-related. A large-scale research based on a survey from tens of thousands of company employees (Barrick \& Mount, 1991; Sutherland et al., 2007; Tuteja \& Sharma, 2017; Karthikeyan \& Srivastava, 2012) on the relationship between the personality traits of the Big-5 and work found that certain personality traits significantly predict the effectiveness of work. The relationship between personality type and social media addiction, stress, and perfectionism in different countries and cultural environments is well discussed by Sumaryanti et al. (2020), Rajesh and Rangaiah (2020), Pollak et al. (2020), Xiao et al. (2019), Stoeber et al. (2009), Lewis and Cardwell (2020), and Stricker et al. (2019).

The dark personality triad concept has focused on three traits: subclinical psychopathy, Machiavellianism, and subclinical narcissism (Paulhus \& Williams, 2002; Prusik \& Szulawski, 2019). Cohen (2016) discussed the correlation between the Dark Triad traits and counterproductive work. The relationship between dark traits and job or school burnout has been examined by Jonason, et al. (2015), Schwarzkopf et al. (2016), Barnett and Flores (2016), Richardson and Boag (2016), and Birkás et al. (2016).

The relationship between dark personality and job performance is a topic of discussion for many researchers (McLarty, 2015; Palmer et al., 2020; LeBreton et al., 2018; O’Boyle et al., 2012; Smith et al., 2016). Templer (2018) discussed the positive direct effect of honesty-humility on the performance measure of team facilitation and support. Guenole (2014) analyzed objections to the Big-5 model in a work context and offered rejoinders that might make researchers and practitioners consider applying this model.

Paleczek et al. (2018), Choi and Nae (2020), Ramos-Villagrasa et al. (2020), Grover and Furnham (2021) explore the relationship between Big-5 and dark personality and job. For example, Zeigler-Hill and Besser (2019) examined the connections between dark personality features and workplace outcomes. Nai and Toros (2020) focused on the profile of a particular type of leader, based on Big-5 and Dark Triad. Brice (2019) argued that perfectionism explains a significant contribution in an additional alternation of the Dark Triad.

Clark et al. (2016), Tziner and Tanami (2013), Stoeber and Damian (2016), and Kang et al. (2020) observed the links between social media addiction, stress, perfectionism, and job performance. For instance, Harari et al. (2018) argued that perfectionism has a significant connection with several organizationally important factors, but an ambiguous connection with job performance. Chang et al. (2016) revealed that healthy perfectionism has a positive effect on the tendency to creative thinking and innovative behavior, while unhealthy perfectionism is associated with constant burnout at work.

Summing up, it should be mentioned that Soto (2018) described how and why the personality traits of the Big-5 develop throughout life and help to predict several important life outcomes. Soto et al. (2011) and Shiner (2015) investigated the stability and changes in the Big-5 over time. Wright et al. (2011) found that consensus has not yet been reached among researchers as to which of the Big-5 factors influences performance.

\section{RESEARCH FRAMEWORK}

This study combines the impact of Big- 5 personality traits (Figure 1) and dark personality traits (Figure 2) in terms of job performance. 


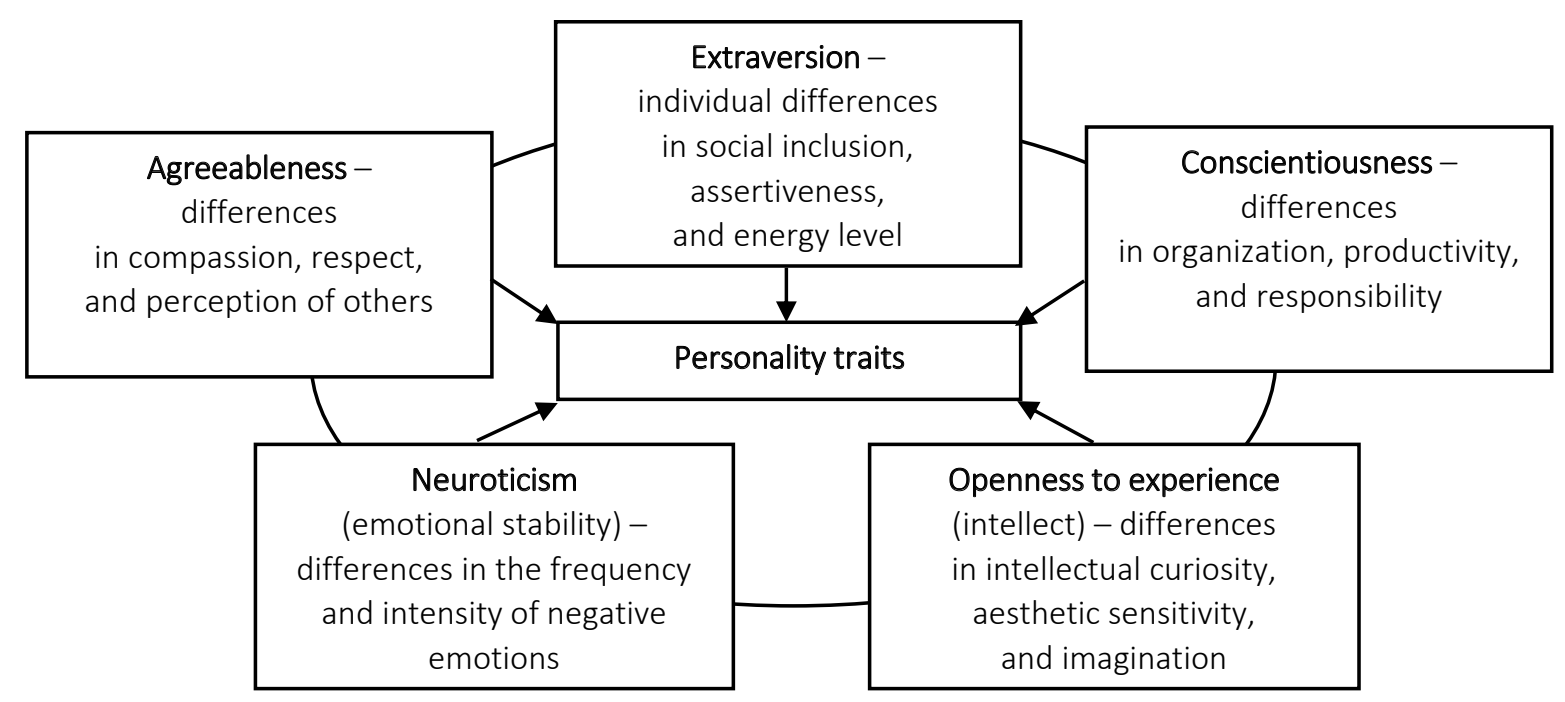

Figure 1. Big-5 personality traits

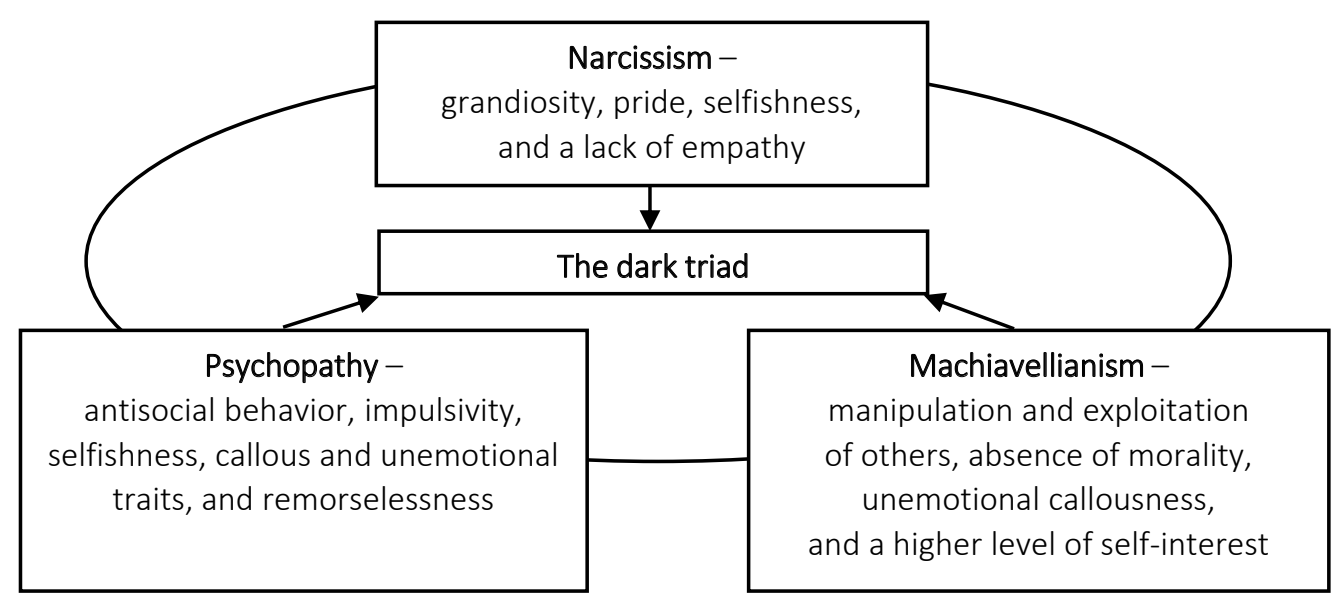

Figure 2. The dark triad (three antisocial personality traits)

\section{METHODS}

\subsection{Participants and procedure}

A total of 514 Turkish private sector adult employees ( $41 \%$ female; older than 21 years old) were recruited for the study via promoting a paper-and-pencil questionnaire in different factories in a Turkish city. The respondents gave their informed consent before participating in the study acknowledging that partaking in the study is anonymous and voluntary. Respondents did not receive any remuneration for participating in the survey. Ethical approval for the study was received from the university's ethical board before the participants' selection and complied with the Helsinki declaration (World Medical Association, 2013).

\subsection{Measures}

Performance Scale (PS): The Turkish form (Çöl, 2008) of the PS (Sigler \& Pearson, 2000) was used to assess employees' job performance. The scale consists of four items (e.g., "I complete my tasks on time", "I make sure that products meet or exceed quality standards") on a 5 -point Likert scale from "never" to "always". The Turkish scale form reported sound psychometric properties (Çöl, 2008). The coefficient of internal consistency in this study showed high values (Cronbach's $\alpha=.76$ ). 
Positive and Negative Perfectionism Scale (PANPS): The Turkish form (blinded for peer review) of the PANPS (Haase \& Prapavessis, 2004) was used to assess perfectionism. The positive perfectionism subscale was used in the present study, which comprises seven items (e.g., "When I am competing against others, I am motivated by wanting to be the best") on a 5-point Likert scale from "absolutely disagree" to "absolutely agree". The Turkish adaptation study reported mostly good fit to the data in the confirmatory factor analysis $\left(\chi^{2}=\right.$ $30.32, \mathrm{df}=9, p<.001$, RMSEA $=.07$ CI 90\% [.05, $.10]$, SRMR $=.03$, CFI $=.99$, GFI $=.98)$. The internal consistency was neither high nor low in the present study $(\alpha=.60)$.

Instagram Addiction Scale (IAS): The unidimensional IAS (Yurdagül et al., 2019) was used to assess problematic social media use by replacing the word "Instagram" with "social media". The IAS consists of six items (e.g., "How often in the past year have you spent a lot of time thinking about social media or planned using social media?") on a 5-point Likert scale from "very rarely" to "very often". It evaluates the components of the dependence (i.e., salience, conflict, withdrawal, mood modification, tolerance, and relapse) is described in the biopsychosocial context of addiction (Griffiths, 2005). The internal consistency coefficient was neither high nor low in this study (Cronbach's $\alpha=.62$ ).

Perceived Stress Scale (PSS): The Turkish form (Küçükusta, 2007) of the PSS (Cohen et al., 1983) was used to measure the stress levels of participants. Even though the original form comprised 14 items, the four-item Turkish form reported good psychometric properties (Küçükusta, 2007). The items (e.g." "I have felt that I was unable to control the important things in my life lately", "I have found that I could not cope with all the things that I had to do") were scored on a 5-point Likert scale from "never" to "always". The internal consistency was very high in the present study (Cronbach's $\alpha=.88$ ).

Dark Personality Traits: Assessment of dark personality traits was performed by adapting the Single Item Narcissism Scale - Turkish (Özsoy et al., 2017; Kircaburun et al., 2021) into all personality traits, including Machiavellianism, psychopathy, sadism, and spitefulness. Personality evalua- tion was highlighted using well-known categories (Marcus et al., 2014; O'Meara et al., 2011; Özsoy et al., 2017). Participants were asked to analyze the extent to which individual traits are consistent with their nature, from $1=$ "absolutely disagree" to 7 = "absolutely agree" (e.g., I am a narcissist $=$ selfish, self-centered; I am Machiavellian = manipulate others and exploit them, lie to achieve own goals at the expense of others; I am psychopath = insensitive to the requests of others, devoid of repentance, indifferent to the morality of actions; I am sadist $=$ enjoy causing intentional harm and pain to others; I am spiteful = ready to harm even myself to harm others).

Big-5 Personality Traits: The dimensions of the Big5 personality traits were analyzed using one item for each personality dimension (i.e., extroversion, neuroticism, agreeableness, openness, conscientiousness). Each personality trait was highlighted using widely known categories (Gosling et al., 2003; Kircaburun et al., 2021). Respondents were asked to rate the extent to which these traits are inherent in them, from 1 = "absolutely disagree" to 7 = "absolutely agree" (e.g., extraversion (e.g., "I see myself as extraverted, enthusiastic"), neuroticism (e.g., "I see myself as anxious, easily upset"), agreeableness (e.g., "I see myself as sympathetic, warm"), conscientiousness (e.g., "I see myself as dependable, self-disciplined"), and openness to experience (e.g." "I see myself as open to new experiences, complex")).

\section{RESULTS}

Descriptive statistics and Pearson's correlation analysis were used to determine mean scores, standard deviations, and correlation coefficients of the study variables (Appendix A, Table A1). Job performance was positively correlated with perfectionism $(r=.17, p<.001)$, agreeableness $(r=.11$, $p<.05)$, and conscientiousness $(r=.10, p<.05)$, and negatively with social media addiction $(r=$ $-.13, p<.01)$, stress $(r=-.19, p<.001)$, neuroticism $(r=-.22, p<.001)$, and psychopathy $(r=-.09, p$ $<.05)$. Next, path analysis with a saturated model was conducted to test the hypothesized relationships (Figure 3). Big-5 personality traits (i.e., extroversion, neuroticism, agreeableness, openness, conscientiousness) and dark personality traits 


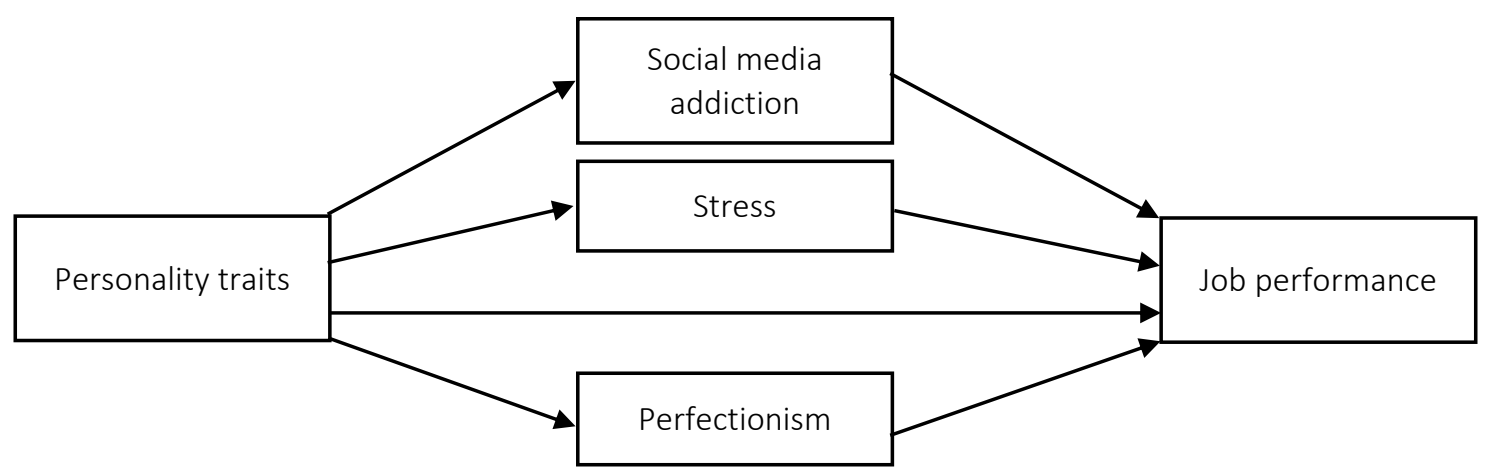

Figure 3. Tested model

(i.e., narcissism, Machiavellianism, psychopathy, sadism, and spitefulness) were the distal factors, social media addiction, stress, and perfectionism were the proximal factors, and job performance was the outcome.

Neuroticism (negatively) was directly $(\beta=-.15, p$ $<.01)$ and indirectly $(\beta=-.06, p<.01)$ related to job performance via stress and social media addiction. Machiavellianism was directly positively $(\beta=$ $.20, p<.001)$ and indirectly negatively $(\beta=-.05, p$ $<.01)$ associated with job performance via social media addiction. Spitefulness was directly positively related to job performance $(\beta=.12, p<.01)$. Furthermore, total effects of extroversion (positively directly and negatively indirectly related to job performance), openness (negatively directly and positively indirectly related to job perfor- mance), and psychopathy (negatively directly and positively indirectly related to job performance) on job performance (Fried et al., 2008) were nonsignificant despite their significant direct and indirect effects (Table 1).

Stress was directly related to neuroticism $(\beta=.20$, $p<.001)$, agreeableness $(\beta=.10, p<.01)$, openness $(\beta=-.22, p<.001)$, psychopathy $(\beta=-.19, p<.001)$, and spitefulness $(\beta=.22, p<.001)$. Social media addiction was directly associated with extroversion $(\beta=.08, p<.05)$, neuroticism $(\beta=.10, p<$ $.05)$, agreeableness $(\beta=.15, p<.001)$, narcissism $(\beta$ $=.18, p<.01)$, Machiavellianism $(\beta=.21, p<.01)$, and psychopathy $(\beta=-.16, p<.01)$. Perfectionism was directly related to extroversion $(\beta=-.11, p<$ $.01)$, agreeableness $(\beta=.19, p<.01)$, narcissism $(\beta$ $=.22, p<.01)$, and sadism $(\beta=-.20, p<.01)$. These

Table 1. Total, direct, and indirect effects of personality traits on job performance

\begin{tabular}{|c|c|c|}
\hline $\begin{array}{rr}\text { Indicators } \\
\end{array}$ & Effect & S.E. \\
\hline Neuroticism $\rightarrow$ Job performance (total effect) & $-.21 * * *$ & .04 \\
\hline Neuroticism $\rightarrow$ Job performance (direct effect) & $-.15^{* *}$ & .04 \\
\hline Neuroticism $\rightarrow$ Job performance (total indirect effect) & $-.06 * * *$ & .02 \\
\hline Neuroticism $\rightarrow$ Stress $\rightarrow$ Job performance (indirect effect) & $-.04 * * *$ & .01 \\
\hline Neuroticism $\rightarrow$ SMA $\rightarrow$ Job performance (indirect effect) & $-.01^{* *}$ & .00 \\
\hline Machiavellianism $\rightarrow$ Job performance (total effect) & $.15^{* *}$ & .04 \\
\hline Machiavellianism $\rightarrow$ Job performance (direct effect) & $.20 * * *$ & .05 \\
\hline Machiavellianism $\rightarrow$ SMA $\rightarrow$ Job performance (indirect effect) & $-.05^{* *}$ & .02 \\
\hline Spitefulness $\rightarrow$ Job performance (total effect) & $.08^{*}$ & .05 \\
\hline Spitefulness $\rightarrow$ Job performance (direct effect) & $.12^{* *}$ & .04 \\
\hline Spitefulness $\rightarrow$ Stress $\rightarrow$ Job performance (indirect effect) & -.03 & .02 \\
\hline Psychopathy $\rightarrow$ Job performance (total effect) & -.09 & .06 \\
\hline Psychopathy $\rightarrow$ Job performance (direct effect) & $-.15^{* *}$ & .06 \\
\hline Psychopathy $\rightarrow$ Job performance (total indirect effect) & $.07 * * *$ & .02 \\
\hline Psychopathy $\rightarrow$ Stress $\rightarrow$ Job performance (indirect effect) & $.03 * * *$ & .01 \\
\hline Psychopathy $\rightarrow$ SMA $\rightarrow$ Job performance (indirect effect) & $.02 * *$ & .01 \\
\hline
\end{tabular}

Note: Only significant effects on job performance are given; SMA = social media addiction; $*$ means $p<.05, * *$ means $p<.01$, $* * *$ means $p<.001$. 
relationships are not illustrated as a table or figure for clarity. The tested model explained $16 \%, 11 \%$, $13 \%$, and $17 \%$ of the variance in stress, social media addiction, perfectionism, and job performance respectively.

\section{DISCUSSION}

The empirical results mostly confirm the intuitive idea that psychologically unstable traits are negatively correlated with performance. At the same time, this finding requires additional conceptualization. For job places, that require psychological resilience and emotional stability, more "flat" personalities are looked preferable. This is relevant mostly for traditional economic and social interactions. The situation may differ in the case of socalled creative industries where talent and personnel admissions may play a more important role. When exceptional creativity coincides with some emotional instability, empirical results of the paper and relevant paradigm may be challenged. It is doubtful that neurotic traits are quite common to hesitate general business performance, but more flexible labor organization and horizontal organizational structures may assimilate destructive traits retaining benefits from creativity.

Also, important to note that the most important drivers of performance (the highest correlation ratio (Appendix A, Table A1) like Agreeableness,
Conscientiousness, and Machiavellianism (after Perfectionism that demonstrates the highest level of correlation)) are challenging trio. Machiavellianism demonstrates the lowest level of correlation meaning that respondents more adherent to traditional employee's values like Agreeableness, Conscientiousness. However, such results may be biased because of the nature of job places and specific requirements to the nature of labor intensity. For example, in the case of traditional industrial job places and traditional offices with hierarchical relations, Agreeableness and Conscientiousness are likely to contribute more to the general success of the organization. While for a freelance model of the economy, Machiavellianism could be potentially more beneficial. The intensity of competitiveness in the job market also could play a role. This study tries to avoid biasing discussion toward cultural dimensions. It means that potentially such traits as Agreeableness, Conscientiousness, and Machiavellianism could be viewed differently in cultures with different attitudes toward hierarchies. Table 1 demonstrates that effect decomposition plays a role on a Machiavellianism side. It means that some relevant traits are important, for example, for career building. At the same time, it is more relevant to assume that economy-mode wins back a more important role in affecting the selection of each trait. Such discussion demonstrates that similar research in the more different economy-mode environment is required.

\section{CONCLUSION}

Transformation of the nature of the job requires a deeper understanding of which traits are more consistent with employee performance. The shift from hierarchies to horizontal structures as well as industrial economy-mode to freelance-mode may affect the rethinking of each trait's contribution to the success of the business. The paper demonstrates that traditional traits stamped as emotional instability mostly negatively correlate with employee performance while more traditional "labor ethic" traits mostly positively. In addition, it was found that in some cases similar patterns like Perfectionism and Narcissism differently contribute to performance. Perfectionism demonstrates the highest level of correlation with performance. At the same time, Machiavellianism traits demonstrate mixed results. From one point of view, such a trait is a less important camper to more traditional hierarchical structures like Agreeableness and Conscientiousness. From another point of view, Machiavellianism demonstrates a strong contribution to performance during the effect decomposition procedure. Such "disappointing" patterns show that Machiavellianism as a trait is inherited by some dualism that may reproduce strong and weak sides in different social environments and different incentive structures. It is assumed that the modality of the economy is more important in that regards camper to, for example, cultural attitudes, but more robust statements in that direction require further research. 


\section{AUTHOR CONTRIBUTIONS}

Conceptualization: Viktor Koziuk.

Data curation: Oleksandr Dluhopolskyi.

Formal analysis: Viktor Koziuk, Serhii Kozlovskyi.

Funding acquisition: Serhii Vitvitskyi, Serhii Kozlovskyi.

Investigation: Mehmet Kiziloglu, Viktor Koziuk.

Methodology: Mehmet Kiziloglu, Serhii Vitvitskyi.

Project administration: Oleksandr Dluhopolskyi, Serhii Kozlovskyi.

Resources: Mehmet Kiziloglu, Serhii Vitvitskyi.

Software: Serhii Kozlovskyi.

Supervision: Mehmet Kiziloglu, Oleksandr Dluhopolskyi.

Validation: Oleksandr Dluhopolskyi, Serhii Vitvitskyi, Serhii Kozlovskyi.

Visualization: Mehmet Kiziloglu, Viktor Koziuk, Serhii Vitvitskyi.

Writing - original draft: Mehmet Kiziloglu.

Writing - review \& editing: Oleksandr Dluhopolskyi, Viktor Koziuk.

\section{REFERENCES}

1. Allport, G. W., \& Odbert, H. S. (1936). Trait-names: A psycholexical study. Psychological Monographs, 47(211). https://doi. org/10.1037/h0093360

2. Andreassen, C. S., Griffiths, M. D. Hetland, J., \& Pallesen, S. (2012). Development of a work addiction scale. Scandinavian Journal of Psychology, 53(3), 265-272. https://doi.org/10.1111/j.14679450.2012.00947.x

3. Barnett, M. D., \& Flores, J. (2016). Narcissus, exhausted: self-compassion mediates the relationship between narcissism and school burnout. Personality and Individual Differences, 97, 102-108. https:// doi.org/10.1016/j.paid.2016.03.026

4. Barrick, M. R., \& Mount, M. K. (1991). The Big Five personality dimensions and job performance: A meta-analysis. Personnel Psychology, 44(1), 1-26. https:// doi.org/10.1111/j.1744-6570.1991. tb00688.x

5. Beer, A., \& Brooks, C. (2011). Information quality in personality judgment: The value of personal disclosure. Journal of Research in Personality, 45(2), 175-185. http://dx.doi.org/10.1016/j. jrp.2011.01.001

6. Birkás, B., Gács, B., \& Csathó, Á. (2016). Keep calm and don't worry: different Dark Triad traits predict distinct coping preferences. Personality and Individual Differences, 88, 134-138. https://doi. org/10.1016/j.paid.2015.09.007

7. Boyle, G. J. (1983). Effects on academic learning of manipulating emotional states and motivational dynamics. The British Journal of Educational Psychology, 53(3), 347-357. https://doi. org/10.1111/j.2044-8279.1983. tb02567.x

8. Boyle, G. J., Stankov, L., \& Cattell, R. B. (1995). Measurement and statistical models in the study of personality and intelligence. In D. H. Saklofske \& M. Zeidner (Eds.), International Handbook of Personality and Intelligence (pp. 417-446). New York: Plenum.

9. Brice, J. A. (2019). Personality and Dark Gaming: The relationships between Perfectionism, the Dark Triad, and Anti-Social Online Gaming Behaviour (Master's thesis). York St. John University. Retrieved from http://ray.yorksj. ac.uk/id/eprint/4371

10. Chang, H.-T., Chou, Y.-J., Liou, J.W., \& Tu, Y.-T. (2016). The effects of perfectionism on innovative behavior and job burnout: Team workplace friendship as a moderator. Personality and Individual Differences, 96, 260-265. http://dx.doi. org/10.1016/j.paid.2016.02.088
11. Cherry, K. (2019). The major leadership theories. The 8 major theories of leadership. VeryWellMind. Retrieved from https://www. verywellmind.com/leadershiptheories-2795323

12. Choi, B. K., \& Nae, E. Y. (2020). When career success enhances employees' life satisfaction: different effects of two types of goal orientations. Personnel Review. https://doi.org/10.1108/PR-042020-0218

13. Clark, M. A., Michel, J. S., Zhdanova, L., Piu, S. Y., \& Baltes, B. B. (2016). All Work and No Play? A Meta-Analytic Examination of the Correlates and Outcomes of Workaholism. Journal of Management, 42(7), 1836-1873. https://doi.org /10.1177\%2F0149206314522301

14. Cohen, A. (2016). Are they among us? A conceptual framework of the relationship between the Dark Triad personality and counterproductive work behaviors (CWBs). Human Resource Management Review, 26(1), 69-85. https://doi. org/10.1016/j.hrmr.2015.07.003

15. Cohen, S., Kamarck, T., \& Mermelstein, R. (1983). A global measure of perceived stress. Journal of Health and Social Behavior, 24(4), 385-396. https://doi. org/10.2307/2136404 
16. Çöl, G. (2008). The effects of perceived empowerment on employee performance. Doğuş University Journal, 9, 35-46.

17. Costa, P. T., Terracciano, A., \& McCrae, R. R. (2001). Gender differences in personality traits across cultures: robust and surprising findings. Journal of Personality and Social Psychology, 81(2), 322-331. https://doi. org/10.1037/0022-3514.81.2.322

18. Cubel, M., Nuevo-Chiquero, A., Sanchez-Pages, S., \& Vidal-Fernandez, M. (2016). Do Personality Traits Affect Productivity? Evidence from the Laboratory. The Economic Journal, 126(592), 654-681. https://doi.org/10.1111/ ecoj.12373

19. DeYoung, C. G., Carey, B. E., Krueger, R. F., \& Ross, S. R. (2016). Ten aspects of the Big Five in the Personality Inventory for DSM-5. Personality Disorders, 7(2), 113-123. https://doi.org/10.1037/ per0000170

20. Epstein, S., \& O’Brien, E. J. (1985). The person-situation debate in historical and current perspective. Psychological Bulletin, 98(3), 513537. https://doi.org/10.1037/00332909.98.3.513

21. Fried, Y., Shirom, A., Gilboa, S., \& Cooper, C. L. (2008). The mediating effects of job satisfaction and propensity to leave on role stress-job performance relationships: Combining meta-analysis and structural equation modeling. International Journal of Stress Management, 15(4), 305-328. https://doi.org/10.1037/a0013932

22. Galton, F. (1884). Measurement of character. Fortnightly Review, 36, 179-185.

23. Goldberg, L. R. (1980). Some ruminations about the structure of individual differences: Developing a common lexicon for the major characteristics of human personality. Symposium presentation at the meeting of the Western Psychological Association. Honolulu.

24. Goldberg, L. R. (1981). Language and individual differences: The search for universals in personality lexicons. In L. Wheeler (Ed.),
Review of Personality and social psychology, 2 (pp.141-165). Beverly Hills, CA: Sage. Retrieved from https://projects.ori.org/lrg/ PDFs_papers/universals.lexicon.81.pdf

25. Gosling, S. D., Rentfrow, P. J., \& Swann, W. B. (2003). A very brief measure of the Big-Five personality domains. Journal of Research in Personality, 37(6), 504-528. https://doi.org/10.1016/S00926566(03)00046-1

26. Griffiths, M. (2005). A 'components' model of addiction within a biopsychosocial framework. Journal of Substance use, 10(4), 191-197. https://doi. org/10.1080/14659890500114359

27. Grover, S., \& Furnham, A. (2021). Personality at home vs. work: Does framing for work increase predictive validity of the Dark Triad on work outcomes? Personality and Individual Differences, 169, 109848. https://doi.org/10.1016/j. paid.2020.109848

28. Guenole, N. (2014). Maladaptive Personality at Work: Exploring the Darkness. Industrial and Organizational Psychology, 7(1), 85-97. https://doi.org/10.1111/iops.12114

29. Guilford, J. P. (1949). The GuilfordZimmerman temperament survey. Sheridan Psychological Services.

30. Gupta, N., \& Gupta, A. K. (2020). Big Five personality traits and their impact on job performance of managers in FMCG sector. International Journal of Recent Technology and Engineering (IJRTE), 8(5), 3104-3109. Retrieved from https://www.ijrte.org/ wp-content/uploads/papers/v8i5/ E6406018520.pdf

31. Haase, A. M., \& Prapavessis, H. (2004). Assessing the factor structure and composition of the Positive and Negative Perfectionism Scale in sport. Personality and Individual Differences, 36(7), 1725 1740. http://dx.doi.org/10.1016/j. paid.2003.07.013

32. Harari, D., Swider, B. W., Steed, L. B., \& Breidenthal, A. P. (2018). Is Perfect Good? A Meta-Analysis of Perfectionism in the Workplace. Journal of Applied Psychology,
103(10), 1121-1144. https://doi. org/10.1037/apl0000324

33. Jonason, P. K., Wee, S., \& Li, N. P. (2015). Competition, autonomy, and prestige: mechanisms through which the Dark Triad predict job satisfaction. Personality and Individual Differences, 72, 112116. https://doi.org/10.1016/j. paid.2014.08.026

34. Joubert, T., \& Venter, N. (2013). The Occupational Personality Questionnaire. In S. Laher \& K. Cockcroft (Eds.), Psychological Assessment in South Africa: Research and applications (pp. 277-291). Wits University Press. https://doi. org/10.18772/22013015782.25

35. Judge, T. A., Bono, J. E., Ilies, R., \& Gerhardt, M. W. (2002). Personality and leadership: a qualitative and quantitative review. The Journal of Applied Psychology, 87(4), 765-780. https://psycnet.apa.org/ doi/10.1037/0021-9010.87.4.765

36. Kang, M., Lee, J., \& Lee, A-R. (2020). The effects of college students' perfectionism on career stress and indecision: self-esteem and coping styles as moderating variables. Asia Pacific Education Review, 21, 227-243. http://dx.doi. org/10.1007/s12564-019-09609-w

37. Karthikeyan, \& Srivastava, D. K. (2012). The relationship between the Five Factors of personality, individual job performance and its components in the Indian corporate sector. International Journal of Advanced Research in Management, 3(1), 37-55. Retrieved from https://www.academia. edu/4932331/THE_RELATIONSHIP_BETWEEN_THE_FIVE_ FACTORS_OF_PERSONALITY_INDIVIDUAL_JOB_PERFORMANCE_AND_ITS_COMPONENTS_IN_THE_INDIAN_ CORPORATE_SECTOR

38. Kenrick, D. T., \& Funder, D. C. (1988). Profiting from controversy. Lessons from the person-situation debate. American Psychologist, 43(1), 23-34. https://doi. org/10.1037/0003-066X.43.1.23

39. Kircaburun, K., Süral, I., March, E., Balta, S., Emirtekin, E., \& Griffiths, M. D. (2021). Study addiction and "dark" personality 
traits: a cross-sectional survey study among emerging adults. Journal of Addictive Diseases, 39(3), 307-315. https://doi.org/10. 1080/10550887.2021.1872469

40. Kline, R. B. (2011). Principles and practices of structural equation modeling ( $2^{\text {nd }}$ ed.). New York: Guilford.

41. Koziuk, V., Dluhopolskyi, O., Farion, A., \& Dluhopolska, T. (2018). Crony sectors as a barrier to economic well-being and ecologization (case of Ukraine). Economics and Sociology, 11(3), 113-132. https://doi.org/10.14254/2071789X.2018/11-3/7

42. Kozlovskyi, S., Bilenko, D., Kuzheliev, M., Ivanyuta, N., Butenko, V., \& Lavrov, R. (2021). Comparison and Assessment of Factors Affecting the COVID-19 Vaccination in European Countries. Problemy Ekorozwoju - Problems of sustainable development, 16(2), 26-33. http://doi.org/10.35784/ pe.2021.2.03

43. Küçükusta, D. (2007). The effects of work-life balance on quality of working life in hospitality organizations (Doctoral dissertation). Dokuz Eylül University, İzmir, Turkey. Retrieved from http:// acikerisim.deu.edu.tr:8080/xmlui/ handle/20.500.12397/5554.

44. LeBreton, J. M., Shiverdecker, L. K., \& Grimaldi, E. M. (2018). The Dark Triad and Workplace Behavior. Annual Review of Organizational Psychology and Organizational Behavior, 5, 387-414. https://doi.org/10.1146/annurevorgpsych-032117-104451

45. Lewis, E. G., \& Cardwell, J. M. (2020). The big five personality traits, perfectionism and their association with mental health among UK students on professional degree programmes. $B M C$ Psychology, 8, 54. https://doi. org/10.1186/s40359-020-00423-3

46. Lucas, R. E., \& Donnellan, M. B. (2009). If the person-situation debate is really over, why does it still generate so much negative affect? Journal of Research in Personality, 43(2), 146-149. https://psycnet.apa. org/doi/10.1016/j.jrp.2009.02.009
47. Marcus, D. K., Zeigler-Hill, V., Mercer, S. H., \& Norris, A. L. (2014). The psychology of spite and the measurement of spitefulness. Psychological Assessment, 26(2), 563-574. https://doi. org/10.1037/a0036039

48. McCrae, R. R., Terracciano, A., \& Personality Profiles of Cultures Project. (2005). Personality profiles of cultures: aggregate personality traits. Journal of Personality and Social Psychology, 89(3), 407-425. https://doi.org/10.1037/00223514.89.3.407

49. McLarty, B. D. (2015). The Devil at Work: Understanding the Dark Side of Personality and its Impact on Performance (Doctoral Dissertation). Louisiana State University.

50. Mehta, P. (2012). Personality as a predictor of burnout among managers of manufacturing industries. Journal of the Indian Academy of Applied Psychology, 32, 321-328.

51. Mischel, W. (1968). Personality and Assessment. Wiley.

52. Musek, J. (2017). The General Factor of Personality. London, England: Academic Press.

53. Nai, A., \& Toros, E. (2020). The peculiar personality of strongmen: comparing the Big Five and Dark Triad traits of autocrats and non-autocrats. Political Research Exchange: an ECPR Journal, 2(1), 1707697. https://doi.org/10.1080/2 474736X.2019.1707697

54. O'Boyle, E. H., Forsyth, D. R., Banks, G. C., \& McDaniel, M. A. (2012). A meta-analysis of the Dark Triad and work behavior: A social exchange perspective. Journal of Applied Psychology, 97(3), 557-579. https://doi.org/10.1037/ A0025679

55. O’Meara, A., Davies, J., \& Hammond, S. (2011). The psychometric properties and utility of the Short Sadistic Impulse Scale (SSIS). Psychological Assessment, 23(2), 523-531. http://dx.doi.org/10.1037/ a0022400

56. Özsoy, E. (2020). Adaptation of the Bergen Work Addiction Scale into Turkish: A validity and reliability testing study. Studies in Psychology, 40(1), 105-125. http://doi. org/10.26650/SP2019-0002
57. Özsoy, E., Rauthmann, J. F., Jonason, P. K., \& Ardıç, K. (2017). Reliability and validity of the Turkish versions of dark triad dirty dozen (DTDD-T), short dark triad (SD3-T), and single item narcissism scale (SINS-T). Personality and Individual Differences, 117, 11-14. http://dx.doi. org/10.1016/j.paid.2017.05.019

58. Paleczek, D., Bergner, S., \& Rybnicek, R. (2018). Predicting career success: is the dark side of personality worth considering? Journal of Managerial Psychology, 33(6), 437-456. https://doi.org/10.1108/ JMP-11-2017-0402

59. Palmer, J. C., Holmes, R. M., \& Perrewé, P. L. (2020). The Cascading Effects of CEO Dark Triad Personality on Subordinate Behavior and Firm Performance: A Multilevel Theoretical Model. Group \& Organization Management, 45(2), 143-180. https://doi. org/10.1177/1059601120905728

60. Paulhus, D. L., \& Williams, K. M. (2002). The Dark Triad of personality: Narcissism, Machiavellianism, and psychopathy. Journal of Research in Personality, 36(6), 556-563. https://doi.org/10.1016/ S0092-6566(02)00505-6

61. Pollak, A., Dobrowolska, M., Timofiejczuk, A., \& Paliga, M. (2020). The Effects of the Big Five Personality Traits on Stress among Robot Programming Students. Sustainability, 12(12), 5196. https://doi.org/10.3390/ su12125196

62. Prusik, M., \& Szulawski, M. (2019). The Relationship Between the Dark Triad Personality Traits, Motivation at Work, and Burnout Among HR Recruitment Workers. Frontiers in Psychology, 10. https:// doi.org/10.3389/fpsyg.2019.01290

63. Rajesh, T., \& Rangaiah, B. (2020). Facebook addiction and personality. Heliyon, 6(1), E03184. https:// doi.org/10.1016/j.heliyon.2020. e03184

64. Ramos-Villagrasa, P. J., Fernández-del-Río, E., \& Barrada, J. R. (2020). Does Evil Prevail? The "Bright" and "Dark" Sides of Personality as Predictors of Adaptive Performance. Sustainability, 
12(2), 474. https://doi.org/10.3390/ su12020474

65. Richardson, E. N., \& Boag, S. (2016). Offensive defenses: the mind beneath the mask of the Dark Triad traits. Personality and Individual Differences, 92, 148-152. https://doi.org/10.1016/j. paid.2015.12.039

66. Sackett, P. R., \& Walmsley, P. T. (2014). Which personality attributes are most important in the workplace? Perspectives on Psychological Science, 9(5), 538-551. http://dx.doi. org/10.1177/1745691614543972

67. Salgado, J. F. (1997). The fivefactor model of personality and job performance in the European Community. Journal of Applied Psychology, 82(1), 30-43. http:// dx.doi.org/10.1037//00219010.82.1.30

68. Schmitt, D. P., Realo, A., Voracek, M., \& Allik, J. (2008). Why can't a man be more like a woman? Sex differences in Big Five personality traits across 55 cultures. Journal of Personality and Social Psychology, 94(1), 168-178. http://dx.doi. org/10.1037/a0014651

69. Schwartz, H. A., Eichstaedt, J. C., Kern, M. L., Dziurzynski, L., Ramones, S. M., Agrawal, M., Shah, A., Kosinski, M., Stillwell, D., Seligman, M. E., \& Ungar, L. H. (2013). Personality, gender, and age in the language of social media: the open-vocabulary approach. PLOS ONE, 8(9), 737-791. https://doi.org/10.1371/journal. pone. 0073791

70. Schwarzkopf, K., Straus, D., Porschke, H., Znoj, H., Conrad, N., Schmidt-Trucksäss, A., \& Känel, R. (2016). Empirical evidence for a relationship between narcissistic personality traits and job burnout. Burnout Research, 3(2), 25-33. https://doi.org/10.1016/j. burn.2015.12.001

71. Shiner, R. L. (2015). The development of temperament and personality traits in childhood and adolescence. In M. Mikulincer, P. R. Shaver, M. L. Cooper \& R. J. Larsen (Eds.), APA handbook of personality and social psychology, 4 (Personality processes and individual differences) (pp. 85-105) Washington, DC: American Psychological Association. https://doi. org/10.1037/14343-004

72. Shrout, P. E., \& Fiske, S. T. (1995). Personality research, methods, and theory. Psychology Press.

73. Sigler, T. H., \& Pearson, C. M. (2000). Creating an empowering culture: examining the relationship between organizational culture and perceptions of empowerment. Journal of Quality Management, 5(1), 27-52. https://doi.org/10.1016/S10848568(00)00011-0

74. Smith, M. B., Wallace, J. C., \& Jordan, P. (2016). When the dark ones become darker: How promotion focus moderates the effects of the dark triad on supervisor performance ratings. Journal of Organizational Behavior, 37(2), 236-254. https://doi.org/10.1002/ job.2038

75. Soto, C. J. (2018). Big Five personality traits. In M. H. Bornstein, M. E. Arterberry, K. L. Fingerman \& J. E. Lansford (Eds.), The SAGE encyclopedia of lifespan human development (pp. 240-241). Thousand Oaks, CA: Sage. Retrieved from https://www.colby.edu/psych/wpcontent/uploads/sites/50/2018/03/ Soto_2018.pdf

76. Soto, C. J., John, O. P., Gosling, S. D., \& Potter, J. (2011). Age differences in personality traits from 10 to 65: Big-Five domains and facets in a large cross-sectional sample. Journal of Personality and Social Psychology, 100(2), 330-348. https://doi.org/10.1037/a0021717

77. Spurk, D., \& Abele, A. E. (2011). Who Earns More and Why? A Multiple Mediation Model from Personality to Salary. Journal of Business and Psychology, 26, 87-103. https://psycnet.apa.org/ doi/10.1007/s10869-010-9184-3

78. Stoeber, J., \& Damian, L. E. (2016). Perfectionism in Employees: Work Engagement, Workaholism, and Burnout. In F. M. Sirois \& D. S. Molnar (Eds.), Perfectionism, health, and well-being. Springer (pp. 265-283). New York: Springer. Retrieved from https://kar.kent. ac.uk/43727/
79. Stoeber, J., Otto, K., \& Dalbert, C. (2009). Perfectionism and the Big Five: Conscientiousness predicts longitudinal increases in self-oriented perfectionism. Personality and Individual Differences, 47(4), 363-368. https://doi.org/10.1016/j. paid.2009.04.004

80. Stricker, J., Buecker, S., Schneider, M., \& Preckel, F. (2019). Multidimensional Perfectionism and the Big Five Personality Traits: A Meta-analysis. European Journal of Personality, 33(2), 176-196. https:// doi.org/10.1002/per.2186

81. Sumaryanti, I. U., Azizah, S., Diantina, F. P., \& Nawangsih, E. (2020). Personality and Social Media Addiction Among College Students. Proceedings of the 2nd Social and Humaniora Research Symposium (SoRes 2019), 376379. https://doi.org/10.2991/ assehr.k.200225.079

82. Sutherland, R., Bruin, G., \& Crous, F. (2007). The relation between conscientiousness, empowerment and performance. SA Journal of Human Resource Management, 5(2), 60-67. http://dx.doi. org/10.4102/sajhrm.v5i2.120

83. Templer, K. J. (2018). Dark personality, job performance ratings, and the role of political skill: An indication of why toxic people may get ahead at work. Personality and Individual Differences, 124, 209-214. https://doi.org/10.1016/j. paid.2017.11.030

84. Tuteja, N., \& Sharma, P. K. (2017) Linking job performance and Big Five personality traits of employees in Chandigarh IT sector. Scholarly Research Journal for Humanity Science \& English Language, 6(26), 7358-7370. http://dx.doi. org/10.21922/srjhsel.v6i26.11443

85. Tziner, A., \& Tanami, M. (2013). Examining the links between attachment, perfectionism, and job motivation potential with job engagement and workaholism. Revista de Psicología del Trabajo y de las Organizaciones, 29(2), 65-74. https://doi.org/10.5093/tr2013a10

86. Vinchur, A. J., Schippmann, J. S., Switzer, F. S., \& Roth, P. L. (1998). A meta-analytic review of predictors of job performance for sales- 
people. Journal of Applied Psychol ogy, 83(4), 586-597. https://doi. org/10.1037/0021-9010.83.4.586

87. World Medical Association. (2013). World Medical Association Declaration of Helsinki: Ethical Principles for Medical Research Involving Human Subjects. JAMA, 310(20), 2191-2194. http:// doi.org/10.1001/jama.2013.281053

88. Wright, E. W., Domagalski, T. A., \& Collins, R. (2011). Improving Employee Selection With a Revised Resume Format. Business Communication Quarterly, 74(3), 272-286. https://doi.org/10.1177/1 080569911413809
89. Xiao, J., Li, D., Jia, J., Wang, Y., Sun, W., \& Li, D. (2019). The role of stressful life events and the Big Five personality traits in adolescent trajectories of problematic Internet use. Psychology of Addictive Behaviors, 33(4), 360-370. https://doi. org/10.1037/adb0000466

90. Yohannes, A. (2020). The effect of personality traits on employees job performance: gender as a moderator, in selected Bureaus of Amhara national regional state (Master's thesis). Bahir Dar University, Ethiopia.

91. Yurdagül, C., Kircaburun, K., Emirtekin, E., Wang, P., \& Grif- fiths, M. D. (2019). Psychopathological consequences related to problematic Instagram use among adolescents: The mediating role of body image dissatisfaction and moderating role of gender. International Journal of Mental Health and Addiction. https://doi.org/10.1007/s11469019-00071-8

92. Zeigler-Hill, V., \& Besser, A. (2019). Dark personality features and workplace outcomes: The mediating role of difficulties in personality functioning. Current Psychology. https://doi. org/10.1007/s12144-019-00527-Z

\section{APPENDIX A}

Table A1. Mean scores, standard deviations, and Pearson's correlations of the study variables

\begin{tabular}{|c|c|c|c|c|c|c|c|c|c|c|c|c|c|c|}
\hline Indicators & 1 & 2 & 3 & 4 & 5 & 6 & 7 & 8 & 9 & 10 & 11 & 12 & 13 & 14 \\
\hline Job performance & - & - & - & - & - & - & - & - & - & - & - & - & - & - \\
\hline Perfectionism & $.17 * * *$ & - & - & - & - & - & - & - & - & - & - & - & - & - \\
\hline SMA & $-.13^{* *}$ & $.18^{* * *}$ & - & - & - & - & - & - & - & - & - & - & - & - \\
\hline Stress & $-.19 * * *$ & .03 & $.47 * * *$ & - & - & - & - & - & - & - & - & - & - & - \\
\hline Extroversion & .08 & -.06 & .04 & -.06 & - & - & - & - & - & - & - & - & - & - \\
\hline Neuroticism & $-.22 * * *$ & -.06 & .06 & $.21^{* * *}$ & $-.14^{* *}$ & - & - & - & - & - & - & - & - & - \\
\hline Agreeableness & $.11^{*}$ & $.23^{* * *}$ & $15^{* *}$ & .06 & .03 & -.08 & - & - & - & - & - & - & - & - \\
\hline Openness & .01 & .08 & -.08 & $-.22 * * *$ & $.20 * * *$ & $-.14^{* *}$ & $.17^{* * *}$ & - & - & - & - & - & - & - \\
\hline Conscientiousness & $.10^{*}$ & $.10^{*}$ & -.05 & -.05 & .07 & $-.21^{* * *}$ & $.16^{* * *}$ & $.36^{* * *}$ & - & - & - & - & - & - \\
\hline Narcissism & .00 & $.16^{* * *}$ & $.17^{* * *}$ & $.11^{*}$ & $-.15^{* *}$ & -.07 & -.01 & $-.27 * * *$ & $-.26 * * *$ & - & - & - & - & - \\
\hline Machiavellianism & .08 & -.08 & $.17^{* * *}$ & $14^{* *}$ & $-.21^{* * *}$ & .03 & $-.11^{*}$ & $-.28 * * *$ & $-.23^{* * *}$ & $.29 * * *$ & - & - & - & - \\
\hline Psychopathy & $-.09 *$ & .01 & -.06 & -.02 & $-.27 * * *$ & $.13^{* *}$ & $-.22 * * *$ & $-.26 * * *$ & $-.24 * * *$ & $.36^{* * *}$ & $.38^{* * *}$ & - & - & - \\
\hline Sadism & -.01 & $-.13^{* *}$ & .03 & .08 & $-.36 * * *$ & -.05 & $-.18^{* * *}$ & $-.31^{* * *}$ & $-.27 * * *$ & $.34 * * *$ & $.57 * * *$ & $.50 * * *$ & - & - \\
\hline Spitefulness & .00 & .01 & -.00 & $.22 * * *$ & $-.30 * * *$ & $.19 * * *$ & $-.15^{* *}$ & $-.13^{* *}$ & -.09 & $.18^{* * *}$ & $.22 * * *$ & $.33 * * *$ & $.31^{* * *}$ & - \\
\hline $\mathrm{M}$ & 4.42 & 3.85 & 1.67 & 1.78 & 5.94 & 2.29 & 4.91 & 5.90 & 5.90 & 1.50 & 1.56 & 1.41 & 1.34 & 1.60 \\
\hline SD & .54 & .58 & .57 & .80 & 1.64 & 1.83 & 1.92 & 1.36 & 1.42 & 1.04 & 1.32 & 1.06 & .99 & 1.27 \\
\hline
\end{tabular}

Note: SMA = social media addiction; * means $p<.05,{ }^{* *}$ means $p<.01, * * *$ means $p<.001$. 